\title{
Barefoot in the Overlay: The Perfect Digital City and the Ruins of Public Space.
}

\author{
Adam Brown
}

James Cook University

\begin{abstract}
Digitally generated views of Townsville's recent city centre redevelopment attempt to overlay visions of a European urban space on the contested territory of the tropical city. Such views obscure the site of an uneven relationship between the various communities which inhabit the city space, by representing a space of apparent completeness and fixity. Applying insights from critical spatial studies and psychogeography, such representations of the city appear to ossify public discourse rather than work towards the creation of genuine multi user spaces, which are always problematic to successfully design and visualise.
\end{abstract}

$\mathrm{T}$ he production of computer generated renderings of architectural or urban development projects enables urban planners to conceptualise, design and promote particular projects and generate community or commercial interest. The increasing sophistication of such models makes them virtually indistinguishable from photographs, but as they become more photograph-like, they become increasingly entangled in particular problematics surrounding photography's claim to represent a pre-existing 'real'. Such images, in borrowing the appearance and mechanisms of photography, could be described as a form of photography 'before the event', and as such operate in a distinct, and strange, rhetorical space. Such signifiers of the photographic represent an appeal to photography's role as final word, as proof, as document.

Issues of visibility, presence and absence are paramount here - the rendering, as with the photograph, struggles to represent that which is not visible. However, it is an operation of a different order to represent that which will not be seen, as opposed to that which cannot be seen. If, as Barthes claims, (Barthes 1957) the uncontextualised practice of photography obscures social and political narratives, then so can the rendering. In the redevelopment of Townsville city centre, efforts to improve the appearance of the CDB are linked to legislation and planning maneuvers designed to reduce the visibility of 'anti-social behaviour' or the presence of people exhibiting such designated behaviour from the city centre. In this paper, I will explore the resonances between the deliberate exclusion of certain sections of the population from a tropical city centre, and exclusions of representations of the 'anti social' from the perfected world of the 3D model.

\section{Location: Flinders Mall:}

Townsville, the unofficial capital city of North Queensland, is a coastal city of approximately 200,000 inhabitants, situated 1300 kilometres north of Brisbane along the Bruce Highway. As a garrison town, and hub of a region reaping the benefits of the current mining boom, it has large transient population, and a relatively small quota of residents were born here - in 2006, 
$55 \%$ of the population had migrated internally within the past 5 years. (ABS, 2006)

Established in 1864 as a port to service the cattle industry, it served as a base for its founder, Robert Towns, to establish his agricultural interests in the region. As a town based on trade, in particular as a channel for the products of the primary industries, the principles of free trade have also governed urban planning.

Townsville has for many years suffered from a tropical version of the doughnut effect, the well documented drain of commerce, services and civic life from the physical city centre which occurs when planning regulation fails to control the development of out of town facilities and shopping centres. (Salt 1992, 64) In order to revive the 'dead centre' of Townsville, in 2008 the council approved a plan to implement a \$56 million regeneration plan for Flinders Mall, the original 'main street', which had for a long time suffered underuse and neglect. Architects Cox Rayner were commissioned and urban designers Gamble McKinnon Green given responsibility for street architecture and planting. Controversially based around the reopening of the centre to motor vehicles after 30 years of pedestrianisation, the project was completed in 2011 and opened with a public carnival, featuring culturally diverse performers, a firework display and a parade of vintage automobiles amongst other events.

\section{Observation 1: a city like any other.}

My key argument is prompted by what would seem to be two very simple observations. The first is that the projected three-dimensional vision of the centre of this tropical city resembles nothing so much as Nottingham, Northampton (my hometown), or any other large town or small city in the United Kingdom. Very little in the redesign seems to stress the specificity of the city or any particular environmental features which would make it identifiable as a tropical location, and very little the specific demographic make-up of its population. This paper does not make claims against a lack of imagination on the part of planners and designers, so much as attempt to explore the ways in which contemporary construction and rendering technologies themselves promote the homogenization of design and locality.

That Townsville looks very much like anytown UK should come as no surprise to anyone familiar with the commentary of Anna Minton. In the United Kingdom:

'lack of local government involvement and planning controls .. and the removal of planning restrictions on out-of-town development result .. in the creation of remarkably similar places, ... not only the places developers wanted but .. the 'nonplaces' identified by Marc Auge - malls, airports, conference centres and, in the new century, central parts of the city. These places are everywhere but feel like they are nowhere in particular, devoid of local culture and history and the distinctiveness that brings.' (Minton, 186)

It is pertinent to recognize that there is a direct correlation between the uptake of computerized construction and rendering technologies and the increased volume and visibility of images of other spaces within new communication media. It is no coincidence that the phenomenon of the contemporary 'superstar architect' or urban developmental megaproject, coincides with the development of technologies which align imaging and automation with construction. If architects such as Rem Koolhaas and others can be described by some commentators as 'new pragmatists,' (Baird, 2007) it is due to a pragmatism which emphasizes the need to build as over-riding any other priorities, and 
significantly the need to be seen to build. Such projects represent huge signifiers of development and economic activity, almost above and ahead of their function as buildings.

That buildings are both designed and visualized on the same platform is significant of the alignment of construction and visualization technologies. In a perceptive article the architect and critic Tor Lindstrand remarks that, in recent developments, 'the representation of objects as we see them and their measured description, two tasks that are conventionally distinguished in architectural drawing, will be shown to have been unwittingly, and in many respects mutually determined and transformed' (Lindstrand, 2007). The implications of this for the politics of the representation of the built environment are enormous, as practices of projection are now in direct collision with those of representation: time is somehow warped. In this single movement, the necessity to invoke the politics of the visible in the context of architectural representation becomes glaringly obvious to the critical onlooker.

\section{Observation 2: transient space}

The second observation concerns not so much the image as the intersection of the city with networks of transport and communication. Townsville specifically, maybe because of its remoteness from major urban or economic centres, or its transient population, seems to exist in a space which floats somewhere off the ground. Everything, especially food and consumer goods, needs to be shipped in by road or rail, leading to unusual 'gluts' or 'droughts' of consumables. If the urban sprawl of the city attests to one thing, it is the spread of infrastructural technologies across geographical space. Lines of electronic communication, power lines, and the ubiquitous road grid allow the city to exist, not grounded on Country, but suspended in mediaspace. As the architectural renderings produced by the planners key into this form of space, Townsville levitates just that bit further off the ground.

To define what I mean by the overlay in relation to Townsville, it is possible to identify a number of key environmental signifiers which increase the effect of the absent on the present.:

- A reliance on automotive transport, and the development of urban sprawl at the expense of pedestrian transit and public transport.

- The maintenance of an interior climate similar to that of a European city by the deployment of air conditioning in the majority of homes, automobiles and especially in the proliferating malls.

- The predominance of cabling of various sorts - the domestic space becomes the location to which one retreats to connect with media - broadband, cable / satellite TV - all of which exist to relay images from elsewhere. The notion of home as a space sufficient in and of itself is diminished.

- The development of a culture of property speculation and investment, not quite yet on the scale of the American / European model but significant. Key indicators would include the speculative renovation of older, classic properties of 'Queenslander' design in areas such as Hermit Park.

- The phenomenon of accelerated planning and development under discussion in this paper.

These signifiers together indicate a move away from fixity and the specifics of locality, to a fast moving, fluid and mobile definition of urban space consistent with the global redefinition of the city as less a place and more a hub. 
For Virilio, the increasing ephemerality of architecture is a significant symptom of the change of emphasis from stasis to movement in late Capitalism in general:

'Urbanism is in decline, architecture is in constant movement, while dwellings have become no more than anamorphoses of thresholds. In spite of people nostalgic about history, Rome is no longer in Rome, architecture no longer in architecture, but in geometry; the space-time of vectors, the aesthetics of construction is dissimulated in the special effects of the communication machines, engines of transfer and transmission' (Virilio 1991, p. 64)

Critically, Townsville represents the interface between the increasing ephemerality of urban space described by Virilio, and the experience of an indigenous population which makes up between 6 and $7 \%$ of the population of the city, for whom the maintenance of long established links between the social and the spatial is key to a sense of identity and cultural survival.

It is possible here to attempt a direct contrast between the transience of the globalised marketplace and its carrier media, and the importance of notions of Country and place to Australian indigenous culture, described as 'intensely ecological and place-based, being drawn from the living landscape within a framework of profound ancestral and personal relationships with place' (Marker, 2006, in Yunkaporta, 2010). However, such a comparison is complex and nuanced: it is important to avoid any hint of an opposition of 'indigenous / located / pre-media' and 'non-indigenous / ephemeral / globally networked'. With regard to issues of location, Marc Auge warns against the danger of accepting the existence of that which he calls 'anthropological space', a construct which represents...

'The indigenous fantasy of a society anchored since time immemorial in the permanence of an intact soil outside which nothing is really understandable; the ethnologist's illusion of a society so transparent to itself that it is fully expressed in the most trivial of its usages, in any one of its institutions, and in the total personality of each of its members.' (Auge, 44)

Contemporary indigenous experience is at one and the same time connected, located, permanent and transient. What I am attempting to deal with here is the message conveyed by particular representations: my argument centres on the opposition of messages conveyed in imagery, and those in public discourse.

There are, however, important ideas which critical spatial studies can take from an exploration of the issues as they occur on the ground in this location: even in major European or global city centres, the view of place or locality as something to be swept away in the drive for economic growth is a significant phenomenon. In East London, long established communities and subgroups are being displaced to make way for the 2012 Olympic development. What I hope to explore by placing Townsville under the lens are eddies of larger currents.

\section{The overlay as space of exchange:}


Paul Memmott, eminent researcher into indigenous Australian architecture, and the interface between the indigenous community experience and urban space, refers to an observation which aligns with Minton's characterisation of the privatization of the UK's public spaces:

'Coleman contends that 'increasingly it is the market citizen, (or consumer) who is recognised as the legitimate user of public space, while other users (including people experiencing long term homelessness) are not recognised, do not have their uses of public spaces legitimated, and are frequently moved on' (Coleman, quoted in Memmott et al, 2003, p. 21)

Minton, in Ground Control (Minton, 2009), explores the phenomenon of the privatization of the contemporary city centre in the UK and elsewhere. Following a model developed in the United States, many city centres have been redesignated 'Business Improvement Districts', and the control of public functions handed over to private organizations. As a key example, the day to day running of Manchester city centre has been entrusted to a wholly private organization, who employ their own security staff and effectively 'police' the city centre, with their sole aim being to increase profit for themselves and the commercial tenants of the space. For such organizations, 'the trading environment is the public realm, and the public realm is the trading environment', as their own promotional material claims (ibid.)

The key feature of such spaces is the maintenance of an appearance of cleanliness, functionality and order. The design of such a city centre must be hygienic, clean and must exclude undesirable elements. As with any system of signifiers, their legibility is dependent on an audience being educated to understand their significance - which in practice implies that, increasingly, elements of disorder and social friction are not only deemed undesirable, but deemed not proper in the shiny new public space. The phenomenon described by Minton is relevant to Townsville as, even though Flinders Mall is still ostensibly a public space - in that it is not owned (or leased to) a private corporation, the local byelaws which proscribe public drinking, and which require council assent for public gatherings or protest, bring the list of activities for which a public space is intended closer to that of a covered mall. In Townsville, freedom of assembly is promised, and withheld, by Queensland's Peaceful Assembly Act, (QLD 1992) which appears to guarantee the right of free assembly on public property given five days notice, yet gives the City Council the right to withdraw permission to hold an assembly on Council land with no need to reveal or debate its reasons. It is possible to speculate that no-one would think that the absence of political protest in a commercial shopping mall anything to comment upon, as this would not seem to be appropriate to the activity of commerce and trade, however the town square, the street, the boulevard, or the park, would seem to be the domain of activities other than just those associated with commerce. Again, the space becomes significant for what is absent from it: public life.

Furthermore, in Townsville, contested definitions of public space are most evident in the motivation of city authorities to 'clean up' the city centre and make it attractive to investors and consumers. (TB 2011 a) Public discourse in local media focuses on the exclusion of members of undesirable social groups - public place dwellers, street drinkers - from the city centre, due to their negative effect on perceptions of the city, locally and further afield.

(ibid.) Ironically, however, it is in this visual identification of problematic social groups that issues of appearance and reality become problematic.

\section{On country / Barefoot in Flinders:}


What is further absent from the renderings is any reference to specific elements of the diversity of the urban experience of Townsville. In particular, one of the issues which characterises local political debate in Townsville is that of homelessness. One of the catalysts for the redevelopment of the town centre was the visibility of a small community of public place dwellers, continually referred to in local discourse as 'itinerants'. (TB 2011 a, TB 2011b)

The term 'public place dwellers' is promoted by Memmott as a preferrable term to other terms which do not accurately reflect the nature of the indigenous homeless experience. Significantly for this paper, the term 'itinerants' is inaccurate as it neglects or downgrades a category of indigenous homeless people who are not 'passing through', but who see themselves as having 'annexed a territorial niche within public and semi-public spaces which they regard as their permanent home' (Memmott et al, 2003)

I am not going to trawl the local papers and their comments for the abundant evidence of the negative stereotyping of public place dwellers, so much as refer to Memmott, Long and Chambers's comparative study of local government responses to issues of homelessness, in which the authors single out Queensland as defining the problem of homelessness as one of public order, as opposed to social need.

'These indicators and measures indicate that the (Queensland Government's) strategy's focus is not to address 'homelessness', as the document defines it, but to address 'public disorder' or anti-social behaviour in the form of public drunkenness or unlawful behaviour. They further suggest that the strategies documented are reacting to public concern rather than responding to the wider needs of Indigenous public place dwelling people.' (Memmott et al, 2003, 9)

Recent public debate has not shifted in the direction of addressing homelessness either: the issue of public drunkenness has recently led councillors to propose measures such as mandatory detoxification for repeat offenders (TB 2010a ) and the forcible removal of the homeless to locations far from the centre. (TB 2010b)

The ban on public drinking in force in Townsville's CBD and Strand was explicitly put in place to address perceived problems of public disorder and drunkenness. To date, the percentage of people moved on by police or dealt with legally under this bylaw have been predominantly indigenous (TB 2010c) - which would seem to be an anomalous statistic in a garrison town.

A court case in 2010 led to an indigenous woman identified as a 'long term alcoholic' being sentenced to removal to Palm Island, a former mission and prison camp for Indigenous rebels and recidivists. (TB $2010 \mathrm{~d}$ ) The fact that a judge deemed it appropriate to sentence a citizen to removal to a particular place shows the persistence of attitudes in the local establishment which deploy access to place, removal from place, and detention in place as a means of governance and control. Palm island is thus still in use as a de facto place of detention. Significantly, this underlines the continued use of removal, exclusion and transportation as a tool of public policy. Though in 2009, proposals to forcibly impose a curfew on those identified as 'homeless' (the term is taken from the source article) in the CBD were reportedly endorsed by Gracelyn Smallwood Chairwoman of the Townsville Indigenous Human Rights Group, the question remains as to whether this policy is motivated by a desire 
to assist the community of public place dwellers, or primarily to improve the appearance of the CBD. Councillor Dale Last is quoted as claiming that 'homelessness was a blight on the community, especially Flinders Mall which was to be redeveloped and bring the city into a new era.' (TB 2010e)

There are evident parallels with the growing culture of exclusionary practices identified by Minton in the United Kingdom. The price of a town centre germane to consumer society is the exclusion of any evidence of disadvantage, dissent or interference with the pure activity of the consumption. (Minton, 2010) Street dwellers, people attending or instigating political gatherings, groups of young people or photographers, are excluded from the new city centres by the enforcement of byelaws.

The politics of alcohol consumption blur into the politics of ethnicity: alcohol control is deployed as a means of social control. Statistics are available to show that, percentage wise, the incidence of alcoholism and alcohol abuse is higher in the non-indigenous than in the indigenous community in Australia. (AMA 2009) The problematic has more to do with visibility - anti social behaviour, confined to the backyard barbie, is not properly anti social any yet if it occurs in the public space, it is observable, identifiable and can be proscribed. In this observation, the politics of visibility / representation come into full play. In the digital representation of a future public space, the absence of anti-social behaviour in no way accurately represents the actual use of the street post-occupation. It is the aestheticisation of a perfected future, in which all social conflicts, frictions and resistances are levelled by the shared experience of unrestricted commerce. The digital space of the consumer mall reserves no space for a community going through a protracted and painful process of healing.

\section{Being seen to drink / being seen to resist:}

Greenop and Memmott reveal how both social gathering and public drinking are deployed as a strategy of resistance by the Aboriginal community frequenting Musgrave Park, Brisbane:

Musgrave Park continues to be a place of Aboriginal protest, as well as social gathering, and involves uniquely Aboriginal uses of place: people from out of town sometimes camp at Musgrave Park (Aird 2001:127) and even the resistance to, and rejection of settler values is undertaken through the flouting of laws and the drinking of alcohol in public at Musgrave Park. There is resistance, but also persistence of values here 24 , and a unique set of place values which are modern and still living and changing.

This blurring of the line between drinking and resistance - a dangerous strategy, employing as it does self medication with an addictive substance - becomes established only because of the exclusionary practices defined above. A deliberate flouting of the law can only be an act of resistance if that law is perceived to define, identify and discriminate against a particular section of the community. For the flouting of such a law in public, then it is possible to claim that what is being flouted is not a proscription on drinking, but on being seen to drink, by being observed in the act of drinking. If it is possible to legitimate this process as part of the narrative of a community undertaking a process of trauma and healing, I would argue that it is a social necessity to negotiate space for this to be present and visible in the space of the city, and for the community most affected by this to be able to have a voice in how this is effected. Examples exist of facilities being provided in other cities - Darwin and Brisbane to accommodate the homeless - shelves, public toilets and imaginative implementations of 
shade and shelter. (Memmott et al, 2003) By this provision, public space is returned to the public - by facilitating the uses the public wish to make of it in the present moment, not some imaginary, projected perfect citizen - the architects' model.

Bringing this back to the politics of the photographic, the images under discussion legitimate the gaze upon the alcoholic by the non-alcoholic, non-traumatised subject - or more accurately, those onto whom these roles are projected - while simultaneously denying the validity of the view from the position of the observed. There is an imbalance of views, in which a position of social advantage is reinforced by possession of the vantage point. Possession of the vantage point also licenses the definition of terms.

A similar triangulation is described by Martha Rosler in her 1981 essay In, Around and Afterthoughts: on documentary photography. (Rosler, 1992) In this imaginative and angry piece, she delineates the space of New York's Bowery district as a complex network of those gazed upon (the derelicts, the 'public place dwellers'), and those looking on - city authorities, photographic students or Sunday photographers hoping for the perfect shot of the picturesque derelict. In a powerfully argued attack on the alignment of objectification and power in the city, she manages to dismantle the well meaning assumptions of the urban documentarist by revealing the alignment of representational practices with structures of power and the denial of agency. In resisting the conventions of representation, Rosler reconfigures the space of the Bowery as a space of language. Language is precisely what is at stake in Townsville's CBD, in the use of particular contested euphemisms for public place dwellers, in definitions of the public, and in the attempted denial of the visible presence of a disadvantaged social group aligned to their negative representation in public discourse.

\section{Conclusion:}

In the streets of Townsville and in the 3D renderings of the future city space, we could describe a fight between transience and permanence on many levels. Firstly, between constructions of an ephemeral, unary public space, in which difference and conflict are annulled under the banner of consumerism and our stake in the idea of eternal economic growth - and the space of Country: the established and continuous importance of place to the City's indigenous population. The speed of contemporary design and construction processes allow planners and architects to erect permanent structures with great speed, not only making but claiming space. In the alliance of new construction technologies with new imaging technologies, the signifying functions of the image are imported into building. The visibility of form defines the proper in public space, to the exclusion of those who have no such power to conceive, calculate and build. The powerless, in De Certeau's formulation, have to resort to tactics, to navigate the strategies of the urban planners. (de Certeau, 1984) In the Townsville renderings, as in many other similar, great efforts are made to ensure the CGI streets are populated by what, to the eye, appears to be a multi-ethnic CGI populace. However what are missing from the renderings are not visual signifiers of cultural diversity, but signifiers of economic diversity.

It is increasingly pertinent to explore the impact of globally effective construction and communication technologies on peripheral locations. If critical spatial practice predominantly concentrates on the critique of urban centres, it could be argued that images from the so-called periphery constitute the majority experience and need as sustained a critique as those from the centre. A location such as Townsville represents the space of the primary industries, the place of extraction, the origin of resources. Such spaces represent to 
some extent the origin of capital which allows the megastructures - the Bilbaos and post Bilbaos, the Olympic developments, Koolhaas's CCTV building - to come into being. As I argued in my previous paper on the subject (Brown 2012), concentration of capital depends on the flow of capital, and that flow has to come from somewhere.

The renderings in question represent an image of a city centre which has been engineered to project an image of commercial viability, which in its turn is intended to stimulate economic revitalization. An imaginary space built with imaginary money. Maybe for once understanding and insight are more important than imagination.

\section{Works Cited}

ABS (2006) National Regional Profile: Townsville City Part B (Statistical Subdivision), accessed online

at: http://www.abs.gov.au/AUSSTATS/abs@.nsf/Previousproducts/34510Population/ People120042008?opendocument\&tabname=Summary\&prodno=34510\&issue $=2004-2008$ accessed March 172012 by Adam Brown

AMA (2009), Alcohol Use and Harms in Australia (2009) - Information Paper, Australian Medical Association, 22 June 2009, accessed 17 March 2012 by Adam Brown at http://ama.com.au/node/4762

Barthes, R. (1957) The Great Family of Man, in Mythologies, France, Editions de Seuil.

Baird, G., (2007) “Criticality” and its Discontents, in The New Architectural Pragmatism: A Harvard Design Magazine Reader, ed. Saunders, W. S., University of Minnesota Press,

Brown, A (2012), Time Travel on the Installment Plan: the index and future form in building, in Rugg, J. and Martin, C. Spatialities, London, Intellect books.

de Certeau, M. (1984). The Practice of Everyday Life, trans. Steven Rendall, University of California Press, Berkeley

Lindstrand, Tor, (2007) Architecture’s Second life Archinect, Jan 9, 2007

Memmott, P., Long, S., Chambers, C. and Spring, F., (2003) Categories of Indigenous 'homeless' people and good practice responses to their needs, Australian Housing and Urban Research Institute, Queensland Research Centre, November 2003

Memmott, P. (2008) Gunyah, Goondie and Wurley: The Aboriginal Architecture of Australia, Brisbane, University of Queensland Press,

Minton, A. (2009) Ground Control, fear and happiness in the twenty-first century city, London, Penguin 
Rosler, M. (1992) In, Around and Afterthoughts: On Documentary Photography in The Contest of Meaning, ed Bolton, Richard, MIT Press,

QLD (1992), The Peaceful Assembly Act, reprint 1A (1999), Brisbane, Office of the Queensland Parliamentary Counsel

Salt, B. (1992), Population Movements in Non-Metropolitan Australia, Department of Primary Industries and Energy, Australian Government Publishing Service, Canberra

TB 2009a, Curfew plan to curb CBD violence, Lendl Ryan, Townsville, Townsville Bulletin, December 12th, 2009

TB 2011a, Itinerant Inaction, Natalie Wynne, Townsville, Townsville Bulletin May $20^{\text {th }}$ 2011

TB 2011a, Itinerant Inaction, Natalie Wynne, Townsville, Townsville Bulletin May $20^{\text {th }}$ 2011

TB 2011b, Budget: Itinerant problem stays in the dark, Natalie Wynne, Townsville, Townsville Bulletin, July $2^{\text {nd }} 2011$

TB 2010a Mandatory Detox to Fix Homelessness, Lendl Ryan, Townsville, Townsville Bulletin, May $14^{\text {th }} 2010$

TB 2010b Homeless to be moved from Parks, Emily Macdonald, Townsville, Townsville Bulletin Oct $22^{\text {nd }}, 2010$

TB 2010c Pubic Drinking Rife, Emily MacDonald, Townsville, Townsville Bulletin, March $6^{\text {th }} 2010$

TB 2010d Parkie sent to Palm Island to Dry Out, Roanne Johnson, Townsville, Townsville Bulletin, July $17^{\text {th }} 2010$

TB 2010e Forum Bid for Forced Rehab, Andrew Strutton, Townsville, Townsville Bulletin, March 31st

TCC 2011, Townsville City Council Aboriginal and Torres Strait Islander Strategic Action Plan, 2011-2014, Townsville, Townsville City Council, 2011.

Virilio, P., (1991) The Aesthetics of Disappearance, trans. P. Beitchman, New York, Semiotext(e)

Yunkaporta, T. and McGinty, Sue, (2009) Reclaiming Aboriginal Knowledge at the Cultural Interface, The Australian Educational Researcher,Volume 36, Number 2, August 2009 